\title{
An Epidemic of Overbreathing Among Schoolgirls
}

\author{
PETER D. MOSS,* M.B., CH.B., M.R.C.P., D.C.H. ; COLIN P. MCEVEDY,† B.M., B.CH., ACAD.D.P.M.
}

Brit. med. F., 1966, 2, 1295-1300

At midday on Thursday, 7 October 1965, the Blackburn Medical Officer of Health received a phone call from the headmistress of a girls' secondary school. In the earlier part of the morning a few of the girls in the school had complained of feeling dizzy and peculiar, and some had fainted; later in the morning the affection had become epidemic and the girls were going down like ninepins. A medical officer immediately went to the school; the girls looked not only frightened but shocked. Ambulances took 85 of the most severely affected girls to hospital ; the rest of the pupils were dismissed and told not to return until the following Monday. Of the girls taken to hospital all but 34 recovered sufficiently in the course of the afternoon to be sent home. Six required readmission over the week-end and three new cases were taken in during this period, but there were no cases among the girls' families or from the community at large.

On Monday the school reassembled, and in the course of the morning another epidemic broke out, almost identical to the first in character and consequence. Fifty-four girls were taken to hospital ; the school was dismissed for the remainder of the week. Many of the Monday cases had been affected on the Thursday, and, as previously, the symptoms subsided quickly enough to allow the majority to be sent home by the evening. The proportion detained in hospital, however, was slightly higher $-54 \%$ as against $40 \%$. The more severe symptoms were limited to those cases involved for the second time: of the 30 new cases only 11 (37\%) were detained. Though half a dozen cases required readmission over the next few days the rate of discharge was much higher. When the school finally reassembled on the following Monday nearly 60 girls complained of a recrudescence of symptoms, but none required admission, and that was the final event in the sequence.

Viewed in retrospect, the epidemic consisted of three spikes with only an insignificant number of cases between; we refer to these three days as day 1 , day 5 , and day 12 . Inquiries suggested that there had been a premonitory wave of faints the day before the first crisis. On Wednesday, 6 October (day 0), the girls had attended a ceremony in the town's cathedral, and a considerable number had either fainted or felt faint. The complete time course accordingly runs from day 0 to day 12 , when the school reassembled.

\section{Hospital Cases}

On day 1, 85 girls were admitted to hospital within a couple of hours. The striking features were swooning, moaning, chattering of teeth, hyperpnoea, and tetany-the general picture of gross emotional upset. As it was assumed that all but a handful would be discharged by evening, they were put on mattresses on the floor of the nurses' training school. However, the symptoms did not subside as rapidly as expected, and 34 cases required formal admission to the ward that night. By day 4, 20 of the girls were still in the hospital and were continuing to faint or overbreathe to the point of tetany. As attempts to increase the discharge rate led to relapse and readmission, it was accepted that time had to be allowed for the emotional disturbance to die down. On day 5, 54 girls with

- Consultant Paediatrician, Blackburn and District Hospital.

† Senior Registrar, Department of Psychological Medicine, Middlesex Hospital, London. identical symptoms were referred to hospital and 29 detained. Thereafter the decline was steady and approximately exponential. The figures for the whole sequence are given in Fig. 1.

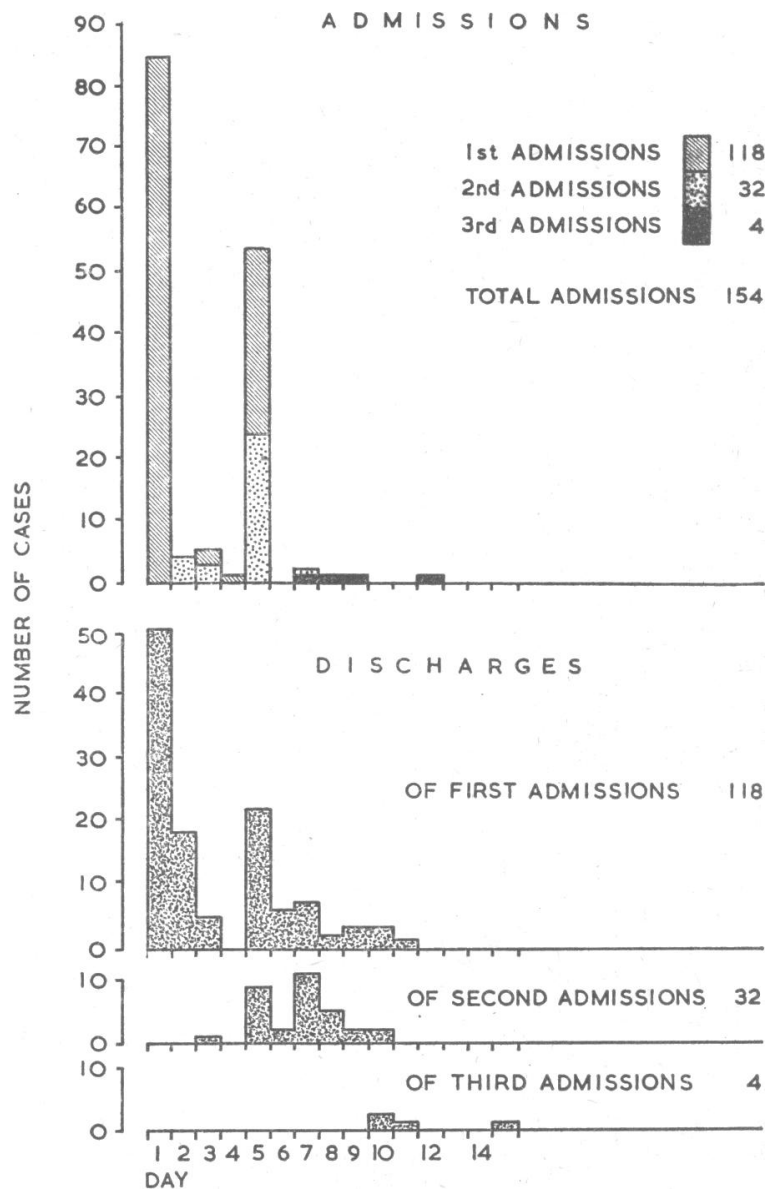

FIG. 1.-Hospital admissions and discharges. (Note that all but 15 of the 154 admissions occurred on days 1 and 5 , and that of these 15 all but 3 were readmissions.)

From the start it was appreciated that most of the girls were hysterical-the psychiatric opinion was obtained on day 2but it was thought that some of the school population had probably been genuinely ill, and that it was the sight of these that had triggered off the hysterical reaction. The search for this organic nucleus proved fruitless. Apart from the hyperventilation and tetany physical examination was essentially negative; there were a few cases of altered sensation of the classical glove or stocking type, and considerably more showed patches of altered sensation on the limbs, but there were no other objective findings. Pyrexia was almost always absent; a small number of girls (fewer than 10) had a low fever, but none had a temperature of over $100^{\circ} \mathrm{F} .\left(37.8^{\circ} \mathrm{C}\right.$.). The white blood count and E.S.R. were done in a minority of cases; the results were all within normal limits. Nine specimens of C.S.F. were taken ; there was no increase in cells or globulin, and the highest protein was $50 \mathrm{mg} . / 100 \mathrm{ml}$. The possibility of a neurotoxic agent from food contaminated by insecticide was considered and six samples 
of blood were examined for cholinesterase content ; all samples were within normal limits.

Throat swabs grew no bacterial pathogens, and 30 such swabs tested by inoculation into $\mathrm{HeLa}$ and monkey-kidney cells grew no viruses. Culture of three C.S.F. specimens was also negative. Of 14 faecal specimens sent for viral culture nine were negative and five positive-one polio type 1 ; two polio type 3 , one Coxsackie B3, and one unidentified. The identified viruses were known to be present in the community, and their isolation is not thought to be significant. Only the girl whose faeces grew the Coxsackie B3 had a fever; this was low-grade and was associated with a sore throat.

Against this entirely negative background it is interesting to consider the list of complaints in order of incidence (see Table). The only overtly emotional complaint-a feeling of paniccomes very low down, but the list as a whole is obviously that of hyperventilation associated with emotional reaction (as opposed to voluntary hyperventilation) (Engel et al., 1947).

Incidence of Main Symptoms

\begin{tabular}{|c|c|c|c|c|c|c|c|}
\hline \multirow{12}{*}{\multicolumn{2}{|c|}{$\begin{array}{ll}\text { Dizziness } & \ldots \\
\text { Fainting } & \ldots \\
\text { Headache } & \ldots \\
\text { Shivering } & \ldots \\
\text { Felt cold } & \ldots \\
\text { Pins-and-needles } \\
\text { Nausea . } \\
\text { Pain in back or abdom } \\
\text { Felt hot ... } \\
\text { Overt hyperventiliation } \\
\text { General weakness } \\
\text { Teeth chattering }\end{array}$}} & & & $\begin{array}{l}\text { No. of } \\
\text { Cases }\end{array}$ & & \multicolumn{2}{|c|}{$\begin{array}{l}\text { No. of } \\
\text { Cases }\end{array}$} \\
\hline & & & .. & & \multirow{2}{*}{$\begin{array}{c}\text { Tetany } \\
\text { Upper and lower limbs }\end{array}$} & .. & \\
\hline & & .. & .. & 91 & & & \\
\hline & & .. & .. & 91 & upper face & 10 & \\
\hline & & .. & $\therefore$ & 78 & & 22 & \\
\hline & & & . & 72 & $\begin{array}{l}\text { Upper and lower limbs } \\
\text { Upper limb only } \quad . .\end{array}$ & 15 & \\
\hline & & .. & & 69 & \multirow{2}{*}{$\begin{array}{c}\text { Lower } \\
\text { Numbness of face" }\end{array}$} & 5 & \\
\hline & & $\ddot{0}$ & $\because$ & 68 & & .. & 48 \\
\hline & & & & 67 & Feeling of panic $\quad \ldots$ & .. & 39 \\
\hline & & & & 66 & \multirow{2}{*}{$\begin{array}{l}\text { Pain in chest or neck } \\
\text { Difficulty in speaking }\end{array}$} & . & 27 \\
\hline & & & & 62 & & .. & 14 \\
\hline & & 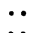 & 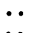 & $\begin{array}{l}62 \\
55\end{array}$ & Vomiting & - & 10 \\
\hline
\end{tabular}

Infrequent sy

The areas of altered (usually diminished) sensation were often surprisingly stable and long-lasting. They tended to be symmetrical, and include one or more of the following:- upper arm: a circular patch over the deltoid, approximately $5 \mathrm{~cm}$. in diameter ; forearm : anterolateral aspect ; hand : thenar eminence and fingertips; thigh and lower leg: anterolateral aspect ; and foot: dorsum.

\section{Epidemiological Investigations}

At a clinical conference held on the Wednesday after the second phase of the epidemic various explanations were considered. One of us has been interested for some time in the phenomenon of mass hysteria and thought that there was a prima-facie case for regarding the outbreak as purely hysterical: the symptoms were predominantly subjective complaints; those affected were adolescent females, a notably susceptible group ; and there were features in the epidemiological pattern that were difficult to explain on an organic basis. A possible cause was to be found in the polio epidemic which the town had suffered earlier in the year and which could be regarded as a significant neurotigenic stress.

The diagnosis of hysteria is usually made by exclusion and on purely negative evidence. It was felt that this epidemic would provide ideal material for an attempt to raise the dignity of hysteria as an epidemiological category. The plan was to make a series of statements which would be true only if the epidemic were hysterical, and then obtain the information to test them decisively.

Before considering these predictions and the results obtained, the terminology and basic theory require an explanation. The word "hysterical" is used by three groups of people in three senses. To the layman it means an exaggerated emotional display ; to the psychiatrist it means a personality distinguished by such displays, by failure in social and sexual relationships, and various more morbid traits; physicians in general and neurologists in particular apply the term to long-standing dysfunctions for which they can find no organic cause, conversion hysteria being the textbook example. It is generally accepted that laymen and psychiatrists are talking about the same class of behaviour, the difference being one of degree. The tendency to histrionic behaviour is presumed to be normally distributed; as we pass from the least to the most hysterical end of the curve the threshold for a hysterical reaction falls. At the end is the morbid group-the psychiatrist's hysterics-who show hysterical behaviour under conditions of normal stress. The physician's hysteric does not position easily on this continuum, which is one of diminishing control over emotionally inspired behaviour, and there are various reasons for thinking that in the determination of hysterical symptoms of a maintained negative type some other personality factor plays a fundamenta! part. From the point of view of this investigation the matter is irrelevant, for mass hysteria, being a phenomenon of the normal population, falls by definition into the first, or layman's, category.

This is an important point, because it means that in searching for pointers to distinguish between the members of a population affected in the course of an outbreak of mass hysteria and those who remained unaffected we can only hope to discover statistical differences: the affected are not pathological and will not show features that distinguish them absolutely. Moreover, the distribution curve is one of the constitution, and hysterical behaviour has to be elicited in the normal by a stress. If a girl's classmates are affected she may respond because the stress on her is high, whereas a girl of identical constitution in an unaffected class will remain uninvolved.

Concerning hysterical constitution, there are two facts and one hypothesis: the facts are that the hysterical reactivity of the female is higher than that of the male, and that from adolescence onwards the reactivity declines; the hypothesis is that of Professor Eysenck, who has defined two axes of personality, $\mathrm{E}$ and $\mathrm{N}$, and predicted that the more hysterical will be found in the high $\mathrm{E} /$ high $\mathrm{N}$ quadrant of his diagram (Eysenck and Claridge, 1962). (E stands for extroversion, $\mathrm{N}$ for neuroticism; scores on both axes are obtained from answers to standardized questionaries.)

Starting from these generalizations, it is possible to make specific predictions about the pattern of a hysterical epidemic. By giving a questionary on the course of the epidemic to the whole school population it was hoped to obtain enough information for the predictions to be fairly tested and the hysterical nature of the outbreak definitely proved or disproved. The Eysenck Personality Inventory (form A) was given at the same time.

There were 589 girls on the school roll, and the questionary was filled in by 552, of whom 17 were absent on both days 1 and 5 . The experimental population is accordingly 535 . On day 1, 519 were present and 141 affected; on day 5, 476 were present and 79 affected. There are six classes in the school, each subdivided into four or more forms, except in the cases of the fifth and sixth classes, which, as relatively few girls stay on after 15, are much smaller than the others. The classes can be translated into age groups by adding 10-that is. the fourth class consists of 14-year-olds.

\section{Predictions and Results}

\section{Constitution}

1. Hysterical reactivity being to a considerable extent constitutionally determined, the same population should be affected on each occasion. This was the only one of the predictions which clinical observation anticipated. However, the degree of overlap between the populations affected on the four days for which data were collected was certainly grossly underestimated. In fact, all of the 25 girls who fainted on day 0 and went to school on day 1 were affected by the day 1 epidemic. It is interesting - and on learning theory understandable-that failure to go to the cathedral had a protective effect so far as 
the later epidemic was concerned. None of the nine girls absent on day 0 and present on day 1 was affected.

Of the 95 girls who were both affected on day 1, and present at school on day 5, 51 were affected in the second much smaller epidemic (total number of cases 79 as against 141 on day 1).

Of the 58 girls who felt ill on day 12, 52 had been affected on days 1 or 5 .

\section{Contagion}

2. The contagion in a hysterical epidemic being behavioural, the epidemic should disseminate more rapidly when the social group is unified than when it is subdivided-that is, the number of new cases should be higher in break periods than in lesson time. Similarly, the majority of cases should occur in public places (the hall, the playground, the corridors, as against classrooms). The initial impression was that neither proposition was true, and that every time and place had yielded its quota of cases. However, though it was correct that sporadic cases occurred throughout the morning and throughout the school buildings, the theoretical expectation received ample support when the questionaries were analysed. Fig. 2 shows that on both days 1 and 5 the number of cases was higher during break than at any other time by a factor of two or more; and, although the ratio of time spent in public places to time spent in classrooms was $4: 7$, the ratio of cases occurring in these times was more than reversed on day 1 at $85: 34$. On day 5 it was $31: 32$; still shifted in the predicted direction, if less convincingly so.

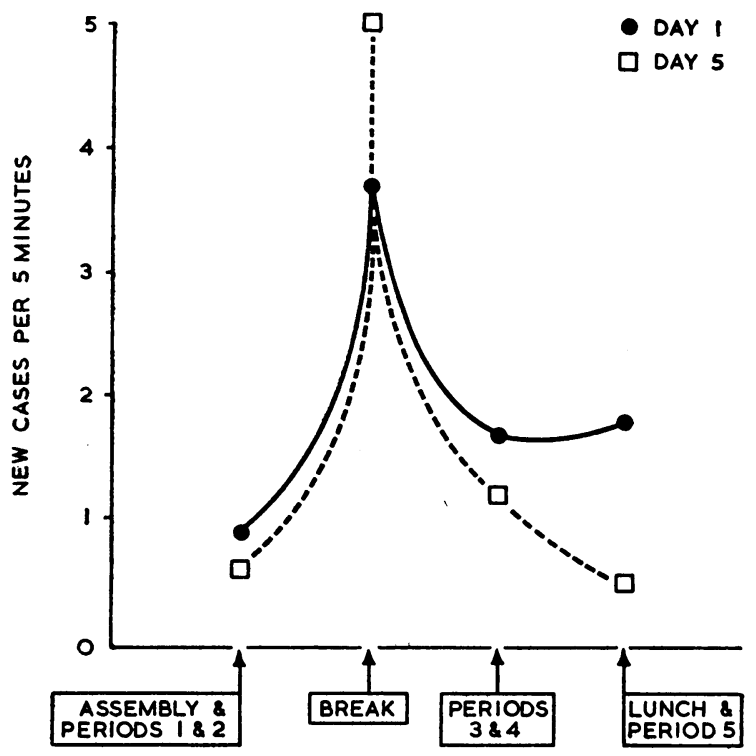

FIG. 2.-Time of onset.

\section{Age}

3. The younger being more susceptible, the incidence of new cases can be expected to move to the lower end of the school as the epidemic progresses. This was the prediction on which most weight was placed, and the concept is worth quantifying in a simple way. If we take an epidemic starting in the middle of the school and consider just the initiating class, we would expect the disturbance to propagate roughly geometrically within this rank, because the stress on its members is proportional to the number affected at any time. In the model in Fig. $3 a$ each successive figure in the central, initiating rank is the sum of those below (preceding it in time). In the senior classes to the left of the initiating rank the epidemic will propagate similarly, but after a time lag. For the junior and more susceptible classes their increased reactivity requires the use of a multiplier-say, two and four respectively for the lower and lowest. In the lowest class each figure thus represents four times the sum of the antecedent cases.

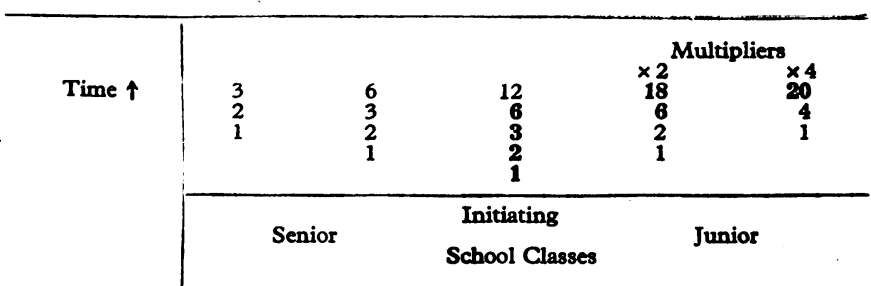

Fic. 3a.-Figures represent new cases in each class in each time perlod.

\begin{tabular}{|c|c|c|c|c|c|c|c|}
\hline $\begin{array}{l}\text { Lunch and period } 5 \\
\text { Periods } 3 \text { and } 4 \quad \ldots \\
\text { Break } \\
\text { Periods } 1 \text { and } 2 \\
\text { Assembly }\end{array}$ & \begin{tabular}{l|l}
$\ldots$ & \\
$\cdots$ & \\
$\cdots$ & \\
$\cdots$ &
\end{tabular} & 1 & $\frac{1}{3}$ & $\begin{array}{r}15 \\
2 \\
3 \\
4 \\
3\end{array}$ & $\begin{array}{r}10 \\
15 \\
3 \\
1 \\
2\end{array}$ & $\begin{array}{r}13 \\
2 \\
3 \\
1 \\
0\end{array}$ & $\begin{array}{r}26 \\
5 \\
2 \\
3 \\
1\end{array}$ \\
\hline School classes & $\ldots$ & 6th & 5th & 4th & 3rd & 2nd & $18 t$ \\
\hline \multicolumn{2}{|c|}{ Number exposed-total 519} & 19 & 23 & 127 & 115 & 111 & 124 \\
\hline
\end{tabular}

FIG. 3b.-Day 1: Total $119+2$ cases late p.m. +20 cases no time stated. Grand Total 141.1

\begin{tabular}{lll|rrrrrrr}
\hline $\begin{array}{l}\text { Lunch and period } 5 \\
\text { Periods } 3 \text { and } 4\end{array}$ & $\ldots$ & $\ldots$ & & & 1 & 4 & 4 & 3 & 7 \\
Break & & 0 & 3 & 7 & 3 & 6 \\
$\begin{array}{l}\text { Periods } 1 \text { and } 2 \\
\text { Assembly }\end{array}$ & $\ldots$ & $\ldots$ & & 1 & 0 & 5 & 3 & 2 & 4 \\
\hline School classes & $\ldots$ & $\ldots$ & & 1 & 3 & 2 & 1 & 2 \\
\hline Number exposed-total 476 & & & 1 & & & 1 \\
\hline
\end{tabular}

FIG. 3c.-Day 5: Total $63+3$ cases late p.m. +13 cases no time stated. Grand Total, $79^{1}$

This model suggests a definite path for a hysterical epidemic -a swing towards the younger end with time. It is gratifying to find that on day 1 this path was followed exactly and convincingly. (In Fig. $3 b$ the number of cases in the sixth and fifth forms needs multiplying by six, because of the small size of these classes.) On day 5 (Fig. $3 c$ ) the pattern is the same, but the epidemic peters out in the last phase. The swing to the right with time is clear enough, however.

A hysterical epidemic that began in the lowest class would of course show no shift. Such epidemics may well occur, but it would seem likely that successfully propagating epidemics run with, rather than against, the grain of a social hierarchy ; the senior are less likely to imitate the junior.

\section{Affected and Unaffected}

4. On the Eysenck hypothesis the reacting girls should score higher in $E$ and $N$. As is shown in Fig. 4, they did so consistently. The narrowing of the gap between the affected and unaffected $\mathrm{E}$ scores towards the younger end is not surprising, as it has been shown that on the junior version of the questionary the standard deviation of the $\mathrm{E}$ scores declines by a full point as the age drops from 16 to 10 (Eysenck, 1965). The various age effects and the uneven incidence of the epidemic can be nullified if the $\mathrm{E}$ and $\mathrm{N}$ scores for each girl are totalled and each form is then ranged in descending order. Fig. 5 shows that when this is done the result is a slope showing a simple relation between form rank in $E+N$ and involvement in the epidemic: nearly $40 \%$ of the girls occupying the higher score places were affected, as against under a quarter in the mean position and under a fifth of those at the lower end of the ranking.

Understandably, the $\mathrm{E}+\mathrm{N}$ score functions best as a predictor in forms where only a few girls are affected; the fewer girls affected, the higher their mean position in the $\mathbf{E}+\mathbf{N}$ ranking (Fig. 6).

1 The figures in heavy type are the highest in each lateral rank. They show a shift to the right or younger end with the passage of time. 
If admission to hospital is taken as an index of severity, the $\mathrm{E}+\mathbf{N}$ scores show no tendency to rise above the means for the affected group as a whole with increasing severity of symptoms. The major factor relating to admission was age: of 115 cases in the upper part of the school 44 (approximately $40 \%$ ) were admitted, as against 22 (approximately $20 \%$ ) out of 113 in the

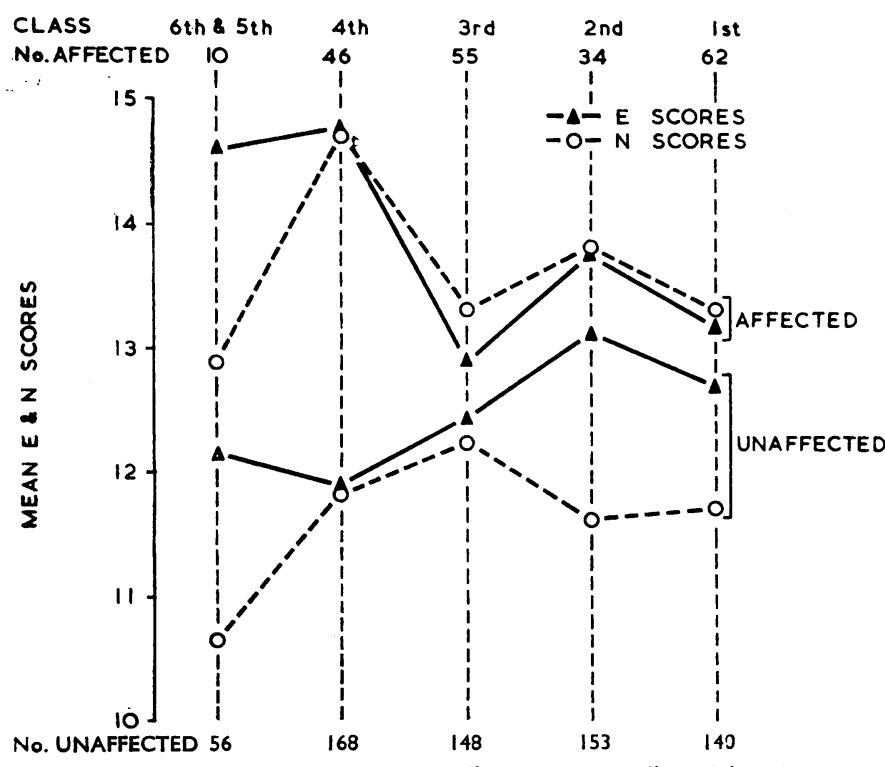

Fig. 4. $-\mathrm{E}$ and $\mathrm{N}$ scores of the affected and unaffected by class.

$$
\begin{array}{lllllllll}
\text { AFFECTED } & \frac{36}{92} & \frac{40}{106} & \frac{40}{127} & \frac{31}{140} & \frac{29}{122} & \frac{14}{73} & \frac{12}{58} & \frac{3}{26}
\end{array}\left[\begin{array}{llll}
\frac{0}{6} & \frac{2}{2}
\end{array}\right]
$$

$\begin{array}{lllllllll}\text { PERCENTAGE } & 39.2 & 37.7 & 31.5 & 22.2 & 23.8 & 19.2 & 20.7 & 11.5\end{array}$
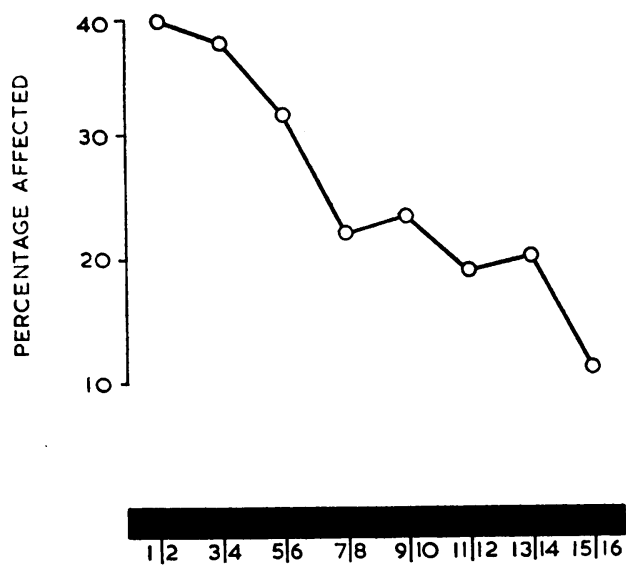

FORM POSITION ON E + N RANKING

FIG. 5.-Incidence in relation to personality position within form.

lower part. The link between severity and age is also apparent in the figures for time in hospital. The class 1 average was 2 days; for class 2 the comparable figure was 3 days; for class 3 it was 3.2 days; and for classes 4,5 , and 6 taken together 3.8 days.

As already mentioned, a second involvement tended to be more severe than a first: the average stay for first admission was 1.2 days, for a second admission 2.2 days, and for a third admission (four cases only) 2.5 days.

These findings are consistent with hysterical reactivity, having a time constant that is proportional to age ; the younger will excite faster, but the disturbance will equally rapidly decline. The more severe second reaction is to be expected from learning theory.

There is a lie scale built into the Eysenck Personality Inventory, and in accordance with Eysenck's recommendation all inventories in which the lie score was six or more were discarded.

\section{Behavioural Morbidity}

5. Although the normality of the population involved has been stressed, there will inevitably be a few individuals in a community of this size who have shown evidence of behavioural morbidity: it was predicted that any girl attending a child guidance clinic would have a higher than average chance of being involved. There were three such girls in the school, and all three fell into the most severely disturbed category, and despite the fact that one was absent from school on day 1 the three piled up a score of six admissions between them. Compare this average of two with the average for the school of 0.12 .
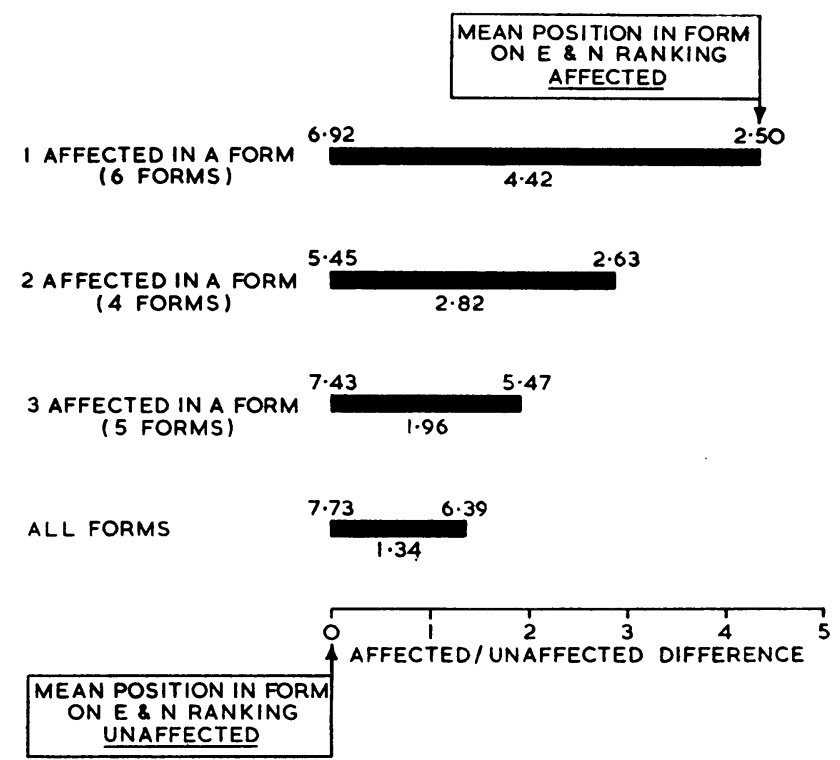

Fig. 6.-Personality position within form of the affected, in relation to number affected per form.

\section{Alternative Theories}

We are now in the position of having positive evidence for hysteria. Is there any positive evidence in favour of any other diagnosis ? Let us look at viruses, food-poisoning, and toxic gases.

A viral theory cannot explain why the girls should have been ill only when at school, and why only these schoolgirls were ill among the local population. Any inoculation must have been prior to day 0 , and it is inconceivable that an epidemic in which cases were almost entirely confined to three mornings could result from a virus present for a period of a fortnight.

Food-poisoning was quickly rejected by the city medical authorities, because of the clinical picture and the fact that many of the affected girls had not eaten at the school. All tests on food and stools were negative.

The only half-way viable alternative to hysteria is poison gas. A gas could cause an epidemic of explosive type confined to a single building, and it could cause symptoms that remitted quickly when the affected were taken elsewhere. But the epidemic occurred in the community rather than in the building: a class of girls at the public baths was affected, and others first felt ill when walking home. On day 12 a dozen guinea-pigs, placed at different points around the school buildings, showed no ill-effects. No poison gas could be found despite careful detective work, nor has there been any trouble in the building since.

A compromise theory-an organic affection with a deal of hysterical overlay-is the last possibility to consider. This type 
of explanation has an immediate appeal ; it is worldly wise and dignified, and comprises the best of all possible worlds. It also saves face and has the advantage of being almost completely untestable. But not quite untestable. If sporadic cases of genuine illness were occurring in the school in the course of the morning one would expect to find proportionately more in the sporadic than in the mass-reaction cases. Yet the fewer girls affected in a class the higher the $\mathrm{E}$ and $\mathrm{N}$ scores of the affected, and the highest scores of all were obtained by the girls who were the only affected members of their class. Moreover, there is a consistency in the symptoms from the very start of the epidemic that makes it inherently unlikely that two different classes of disturbance were operating. To be pragmatic about it, the only tenable postulate for a mixed epidemic is that the number of organic cases was so small that it had no effect, in which case the postulate is of no significance.

\section{Discussion}

The aim of this paper is twofold: to establish the nature of the epidemic and to describe the symptomatology. As for the nature, the fulfilment of patterns predicted for a behavioural epidemic strongly suggests that the outburst was hysterical. In retrospect, the story can be put together as follows:

In the early part of the year there was a polio epidemic in the town. It received widespread coverage in the press, and soon the citizens were reading not only bulletins about the victims but reports of lorry-drivers refusing to deliver supplies to the "polio town" and receiving letters from landladies cancelling their holiday bookings.

All this must have impressed the community as a whole, and had a correspondingly magnified effect on its most susceptible partits schoolgirls. Some of the schools in the town are Catholic, and naturally their girls did not attend when later in the year a ceremony was held in the Anglican cathedral. In the other schools attendance was voluntary, and consequently was only partial. In the school involved in the epidemic, which prides itself on requiring actual rather than nominal adherence to the Church of England, the girls were present, if not quite in toto, with no higher absenteeism than occurs on an ordinary working-day. Unfortunately, the ceremony - under Royal patronage-was delayed by late arrival. The girls, the bulk of them outside the building, waited for some three hours. During this period 20 fainted, at least to the extent that they had to break ranks and lie down. Others felt faint but held their ground. The whole outing must have made a powerful impression, and next day on the morning bus to school one mistress noted (in retrospect) an air of excitement and a great deal of talk about fainting-exactly who had fainted and how many times. The scene was set.

At assembly there was one faint. The prevailing rate for assembly faints in the school is two or three a week, so there was nothing unusual in this. However, after assembly three other girls said they felt dizzy, and when a fourth was asked to get a glass of water for the original fainter she immediately felt faint herself. To this nucleus a further half-dozen girls were added in the course of the first two periods. These girls were sat on chairs in a corridor running through the centre of the building: a mistress thought that rather than run the risk of the girls hurting themselves by falling from the chairs in a second faint they had better lie on the floor. In this state they were on view during the mid-morning break, and at this point the phenomenon became epidemic. It is interesting to note that 10 of the 18 teachers who wrote reports on the morning's events gave the break as the time when they first became aware of anything unusual.

What became epidemic was a piece of behaviour consequent on an emotional state: excitement or, in the latter stages, frank fear led to overbreathing, with its characteristic sequelae-faintness, dizziness, paraesthesiae, and tetany. Once learned, this selfreinforcing piece of behaviour restarted spontaneously whenever the school was assembled. By day 12, however, the hysterical nature of the epidemic was generally accepted, and a firm line prevented the behaviour propagating as extensively as it had on the previous occasions.

Clinically the symptoms are entirely explicable in terms of overbreathing due to emotional tension. The patches of altered sensation were thought to have been clinically valid when initially determined, and are conventionally and convincingly explained by the effect of overbreathing upon the vascular supply of the peripheral nerves. Their maintenance over a period of days is surprising, and could be explained either by repeated bouts of overbreathing-which certainly occurredor as a learning phenomenon, in which abnormal responses were perseverated by anxious patients. In general it seems that, once a reaction of a certain severity has been established, reassurance and nursing care provide the environment necessary for recovery but cannot speed the process. That the slow decline in symptoms is an intrinsic feature of hysterical reactions, and not a function of the care given to these particular cases, is strongly suggested by the fact that both severity and length of stay in hospital were proportional to age. In any case, it is in accord with the experience of psychiatrists, who recognize that when a hysterical reaction has proceeded beyond a certain point hospital admission for a week or so is necessary for recovery, and that the symptoms decline gradually rather than cease abruptly.

This epidemic received a great deal of publicity as a "mysterious illness." It was initially both mysterious and frightening for the girls affected. We hope to have established the behavioural nature of the epidemic beyond reasonable doubt, but we do not wish to suggest that the whole episode was "nonsense." The girls were certainly not malingering: the original observers were not "fooled." The picture of acute hysterical collapse can be exceedingly alarming and, physically, extraordinarily convincing. Even the lay view of hysteria recognizes a point when the victim is unable to control the symptoms and medical care is necessary. It undoubtedly was in this instance.

\section{Summary}

An epidemic of overbreathing among girls at a secondary modern school is described. Approximately a third of a total of 550 girls were affected, many of them on more than one day. About a third of the affected required inpatient care.

Clinical and laboratory findings were essentially negative.

Investigations by the public health authorities did not uncover any evidence of pollution of food or air.

The epidemiology of the outbreak was investigated by means of questionaries administered to the whole school population It was established that the outbreaks began among the 14-yearolds, but that the heaviest incidence moved to the youngest age groups.

By using the Eysenck Personality Inventory it was established that in all age groups the mean $\mathrm{E}$ and $\mathrm{N}$ scores of the affected were higher than those of the unaffected.

The younger girls proved more susceptible, but disturbance was more severe and lasted longer in the older girls.

It was considered that the epidemic was hysterical, that a previous polio epidemic had rendered the population emotionally vulnerable, and that a three-hour parade, producing 20 faints on the day before the first outbreak, had been the specific trigger.

The data collected were thought to be incompatible with organic theories and with the compromise theory of an organic nucleus.

Our first acknowledgement must be to the matron and staff of Park Lee Hospital, who coped most efficiently with the sudden influx of patients. During the subsequent investigations we received the fullest co-operation from the Blackburn medical and educational authorities, and the headmistress and staff of the school involved. Without this co-operation the questionary survey could never have been initiated, let alone carried out. We would specifically like to thank Dr. J. Ardley, Medical Officer of Health for Blackburn, Dr. J. Mountain, Deputy Medical Officer of Health, and Dr. L. P. Grime, Assistant Medical Officer of Health, for help given; 
we also wish to make it clear that the opinions expressed in this article are ours alone.

The cost of the psychiatric side of the programme was defrayed by a grant from the Research Committee of the Middlesex Hospital. We would like to thank Professor A. Kekwick and the members of the committee for making these funds available at very short notice, and for their interest and confidence.

The psychiatric investigation had the benefit of advice from $\mathrm{Dr}$ A. W. Beard, Consultant Psychiatrist at the Middlesex Hospital.
His time and experience were freely given, greatly appreciated, and both administratively and intellectually essential.

\section{REFERENCES}

Engel, G. L., Ferris, E. B., and Logan, M. (1947). Ann. intern. Med., 27, 683.

Eysenck, H. J., and Claridge, G. (1962). 7. abnorm. soc. Psychol., 64, 46. Eysenck, Sybil B. G. (1965). Manual for the funior Eysenck Personality Inventory. Educational and Industrial Testing Service, San Diego. California.

\title{
Two School Epidemics
}

\author{
COLIN P. MCEVEDY,* B.M., B.CH., ACAD.D.P.M.; ALWYN GRIFFITH, $†$ M.B., CH.B., D.P.H. \\ THOMAS HALL, $\ddagger$ M.A., M.B., B.CHIR., D.P.H.
}

Brit. med. Y., 1966, 2, 1300-1302

The epidemic at Blackburn described in the preceding paper was reported in the press with some prominence, and over the period of a week or so in which the item was considered newsworthy illnesses at schouls in other parts of the country were coupled with it. Events at two of these schools-one at Portsmouth and one at Wrexham, Denbighshire-are of interest in relation to theoretical ideas about the epidemiology of hysterical outbursts.

\section{The Portsmouth School}

The school at Portsmouth is a girls-only secondary school with 272 pupils distributed in five classes and 12 forms. As at Blackburn, the age of the girls is obtained by adding 10 to the class number (that is, the fourth class consists of 14-year-olds). On Thursday, 7 October (Day 1), half a form of 13-year-olds became ill in the late afternoon and five were taken to hospital complaining of vomiting and abdominal pain. None was detained. The next day (Day 2) there was an explosive epidemic which started at assembly and involved every class except the fifth during the course of the day ; 72 girls had to be sent home from school. The girls seemed less convincingly ill than the Day 1 cases ; their symptoms were mostly a matter of faintness and feeling peculiar. There was a similar outbreak on the Monday (Day 5: 47 girls sent home) and a trickle of new cases during school hours for the remainder of the week.

Five months after the event $70 \%$ of the girls filled in the Eysenck Personality Inventory and a questionary on the course of the epidemic. As Fig. 1 shows, the questionary results confirmed the clinical impression that there had been exceedingly few new cases during the week-end of Days 4 and 5 . There is consequently good reason for believing that the epidemic was biphasic and linked to school hours.

Interestingly the epidemic was heavier in the A stream (65 out of 138 sent home : $46 \%$ ) than in the B stream (39 out of $134: 29 \%$ ). This effect was consistent in all classes, and is confirmed by the questionary results, though as for every two girls sent home another felt ill the actual incidences are higher (A $63 \%$; B $43 \%$ ).

Pathological and public health investigation of this epidemic yielded only negative results, and the medical officers concerned formed the opinion that, while the girls affected on Day 1 were probably organically ill in some mild gastrointestinal way, the Day 2 and subsequent cases were purely functional.

* Senior Registrar, Department of Psychological Medicine, Middlesex Hospital, London.

+ Medical Officer of Health, Wrexham, Denbighshire.

$\ddagger$ Deputy Medical Officer of Health, Portsmouth, Hants
Time Course in Relation to Age.-The headmistress had lists of the girls sent home on Days 1,2, and 5 which she thought were chronologically accurate (that is, represented the actual order in which the girls were sent home). The Day 1 list does not concern us, as all but 2 of the 14 girls cited were in the same form ; the Day 2 list was checked against the girls'

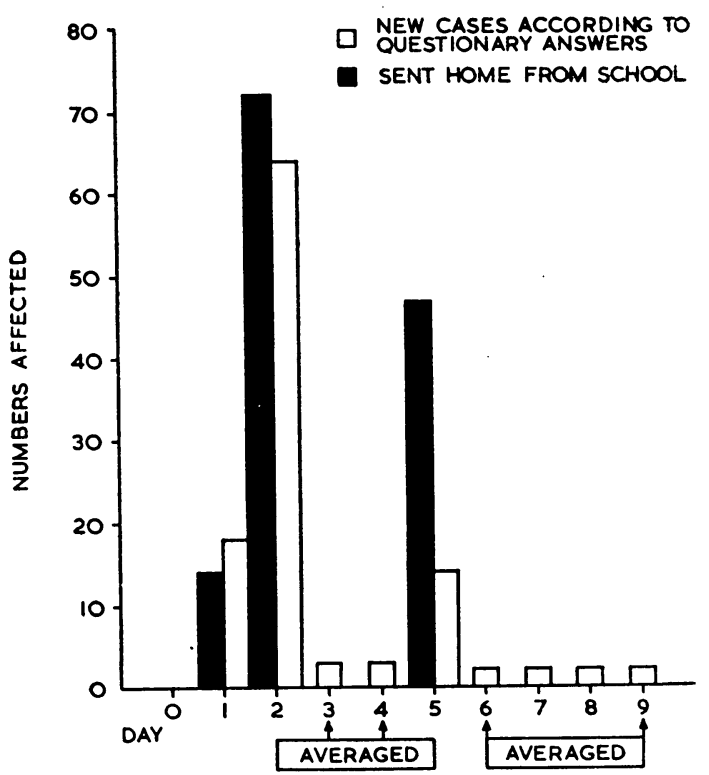

FIG. 1.-Tine course of the Portsmouth epidemic.

questionary answers and found to be chronologically valid (Fig. 2) ; by the same test the Day 5 list was not. The Day 2 list shows a clear shift from the upper to the lower classes with time. The figures are given in Table $I$.

Personality Factors. - The questionary answers indicate that of 40 girls who were present on both Days 2 and 5 and were taken ill on Day 5, 27, or two-thirds, had been ill on Day 2. Half of these had been feeling quite well throughout the weekend. As for the morbid end of the behavioural spectrum, the headmistress supplied two lists compiled from objective data. The first was composed of 18 B-stream girls who had reached a specific level of conduct disorder during the term. Given a B-stream incidence of $29 \%$, the number of these that might be expected to appear on the list of girls sent home is nearer 5 than 6 ; the actual figure is 10 . The second list consisted of 